\title{
PENGETAHUAN DAN SIKAP MASYARAKAT TENTANG UPAYA PENCEGAHAN TUBERKULOSIS
}

\author{
Community's Level of Knowledge and Attitude towards Tuberculosis \\ Prevention Efforts
}

\author{
Fauzie Rahman', Adenan', Fahrini Yulidasari², Nur Laily³, Dian Rosadi', \\ Aulia Noor Azmi ${ }^{5}$ \\ ${ }^{1}$ Administrasi Kebijakan Kesehatan, Prodi Kesmas FK Universitas Lambung Mangkurat \\ ${ }^{2}$ Gizi dan Kesehatan Reproduksi, Prodi Kesmas FK Universitas Lambung Mangkurat \\ ${ }^{3}$ Bagian Promosi Kesehatan, Prodi Kesmas FK Universitas Lambung Mangkurat \\ ${ }^{4}$ Bagian Epidemiologi, Prodi Kesmas FK Universitas Lambung Mangkurat \\ ${ }^{5}$ Mahasiswa Prodi Kesehatan Masyarakat FK Universitas Lambung Mangkurat \\ (fauzierahmankmpk2010@gmail.com)
}

\begin{abstract}
ABSTRAK
Penyakit tuberkulosis paru adalah penyakit menular kronis yang disebabkan oleh bakteri Mycobacterium tuberculosis. World Health Organization (WHO) menyatakan bahwa 1/3 penduduk dunia telah terinfeksi kuman tuberkulosis. Pada tahun 2012 kasus penderita tuberkulosis baru di Kalimantan Selatan dilaporkan 96 per 100.000 penduduk. Tujuan penelitian ini adalah mengetahui hubungan antara tingkat pengetahuan dan sikap dengan upaya pencegahan penyakit tuberkulosis di wilayah kerja Puskesmas Bawahan Selan tahun 2015. Metode penelitian ini adalah kuantitatif dengan pendekatan cross sectional study. Populasi penelitian sebanyak 24.410 orang, teknik pengambilan sampel menggunakan metode cluster random sampling, kemudian jumlah sampel ditentukan menggunakan rumus slovin dan didapat sampel sebanyak 100 orang. Instrumen penelitian menggunakan kuesioner. Hasil penelitian menggunakan uji chi square menunjukkan ada hubungan antara pengetahuan $(\mathrm{p}=0,000)$ dan sikap $(\mathrm{p}=0,000)$, dapat disimpulkan bahwa ada hubungan pengetahuan dan sikap dengan upaya pencegahan tuberkulosis. Kata kunci: Pengetahuan, sikap, pencegahan, tuberkulosis

ABSTRACT

Pulmonary tuberculosis disease is a chronic infectious disease caused by Mycobacterium tuberculosis. The World Health Organization (WHO) states that 1/3 of the world's population has been infected by tuberculosis germs. In 2012, it was reported that new cases of tuberculosis in South Kalimantan amounted to 96 cases per 100,000 population. The purpose of this study is to determine the relationship between the level of knowledge and attitudes towards tuberculosis prevention efforts in the Bawahan Selan Community Health Center work area in 2015. The research method was quantitative with a cross-sectional approach. The population sizewas 24.410 people, which was sampled using the cluster random sampling method. The sample size was determined using the slovin formula, which resulted in a sample size of 100 people. A questionnaire was used as the research instrument. The results from a chi square test showed that there is a relationship between knowledge $(p=0,000)$ and attitude $(p=0,000)$. It can be concluded that there is a relationship between knowledge, attitude, andtuberculosis prevention efforts.
\end{abstract}

Keywords : Knowledge, attitude, prevention, tuberculosis 


\section{PENDAHULUAN}

World Health Organization (WHO) menyatakan bahwa $1 / 3$ penduduk dunia telah terinfeksi kuman tuberkulosis. Setiap tahunnya di seluruh dunia didapatkan sekitar 4 juta penderita baru tuberkulosis paru. Sekitar 3 juta meninggal setiap tahunnya. Saat ini, di negara maju diperkirakan setiap tahun terdapat 10-20 kasus baru setiap 100.000 penduduk dengan kematian 1-5 per 100.000 penduduk, sedangkan di negara berkembang angkanya masih tinggi. ${ }^{1}$

Data Profil Kesehatan Indonesia, prevalensi tuberkulosis paru berdasarkan diagnosis sebesar $0,4 \%$ dari jumlah penduduk. Dengan kata lain, ratarata tiap 100.000 penduduk Indonesia terdapat 400 orang yang didiagnosis kasus tuberkulosis oleh tenaga kesehatan. ${ }^{2}$ Menurut data profil kesehatan Kalimantan Selatan tahun 2012, selama tahun 2011 ditemukan 3.328 penderita tuberkulosis BTA Positif. Hal ini berarti hampir $60 \%$ penderita tuberkulosis BTA positif di Kalimantan Selatan masih belum ditemukan. Kondisi masih rendahnya cakupan penemuan tuberkulosis tersebut memberikan dampak pada peningkatan penyebaran penyakit tuberkulosis. Salah satu penyebab rendahnya cakupan penemuan penderita tuberkulosis tersebut adalah masih rendahnya kesadaran penderita dalam menjalani proses pengobatan dan penyembuhan. Tuberkulosis juga tidak terlepas dari faktor sosial budaya, terutama berkaitan dengan pengetahuan, dan sikap masyarakat setempat. ${ }^{3}$ Puskesmas Bawahan Selan merupakan peringkat pertama di Kabupaten Banjar dengan data penemuan kasus baru tuberkulosis BTA positif pada tahun 2014, dengan persentase sebesar $96,1 \%$ dengan jumlah 49 kasus. Insiden relatif kasus baru BTA positif di wilayah kerja Puskesmas Bawahan Selan terjadi peningkatan yang sangat signifikan pada 3 tahun terakhir. ${ }^{4}$

Faktor pengetahuan, sikap dan perilaku mempunyai pengaruh besar terhadap status kesehatan individu maupun masyarakat dan berperan penting dalam menentukan keberhasilan suatu program penanggulangan penyakit dan pencegahan penularannya termasuk penyakit tuberkulosis. Menurut hasil penelitian Simak bahwa masyarakat yang memiliki pengetahuan yang rendah mempunyai risiko tertular tuberkulosis sebesar 2,5 kali lebih banyak dari orang yang berpengetahuan tinggi, untuk sikap yang kurang 3,1 kali lebih besar berpeluang tertular dari orang yang memiliki sikap yang baik.

Media dalam penelitian terdahulu didapatkan pengetahuan masyarakat mengenai gejala penyakit tuberkulosis relatif cukup baik akan tetapi sikap masyarakat masih kurang peduli terhadap akibat yang dapat ditimbulkan oleh penyakit tuberkulosis sehingga membuat perilaku dan kesadaran masyarakat untuk memeriksakan dahak sebagai salah satu upaya pencegahan penyakit tuberkulosis masih kurang dengan alasan mereka malu dan takut di vonis menderita tuberkulosis. ${ }^{6}$ Wahyuni dalam penelitian terdahulu mengungkapkan bahwa terdapat hubungan yang bermakna antara pengetahuan, sikap, dan tingkat pendidikan dengan pencegahan penularan penyakit tuberkulosis di masyarakat. ${ }^{7}$ Berdasarkan masalah dari latar belakang yang telah diuraikan, dan melihat pentingnya upaya pencegahan penularan penyakit tuberkulosis oleh masyarakat di wilayah kerja Puskesmas Bawahan Selan maka diperlukan penelitian untuk menganalisis tingkat pengetahuan dan sikap masyarakat dengan upaya pencegahan penyakit tuberkulosis di Kabupaten Banjar".

\section{BAHAN DAN METODE}

Rancangan penelitian ini bersifat analitik, dengan pendekatan cross sectional study. Populasi dalam penelitian ini adalah seluruh penduduk yang ada di wilayah kerja Puskesmas Bawahan Selan tahun 2015 sebanyak 24.410 orang. Sampel penelitian ditentukan dengan menggunakan teknik cluster random sampling dengan besar sampel minimal sebanyak 100 sampel dan akan diambil pada Rumah Tangga (RT) dengan menghitung berdasarkan proporsi jumlah tiap RT dengan seluruh populasi desa terpilih dikali jumlah sampel. Instrumen dalam penelitian ini adalah kuisioner atau angket yang telah diuji validitas dan realibilitasnya. Uji validitas dan realibilitas dilakukan di wilayah kerja Puskesmas Karang Intan sebanyak 30 responden. Alasan dipilih 30 responden karena berdasarkan kaidah penelitian jumlah 30 responden adalah batas jumlah antara sedikit dan banyak yang akan mendekati fenomena ciri atau sifat alami yang sebenarnya. ${ }^{8}$

Pada penelitian ini untuk mendeskripsikan pola kecenderungan hubungan variabel bebas dan 
variabel terikat maka dibuat tabel silang. Analisis bivariat untuk mengetahui ada hubungan antara variabel bebas (pengetahuan dan sikap) dengan variabel terikat (upaya pencegahan penyakit). Tahap awal pengujian statistik dilakukan dengan uji chi square dengan uji statistik dengan tingkat kemaknaan $\alpha=0,1$. Penyajian data menggunakan tabel distribusi frekuensi dan tabulasi silang.

\section{HASIL}

Berdasarkan Tabel 1, diketahui bahwa berdasarkan karakteristik responden penelitian ini sebagian besar berjenis kelamin perempuan sebanyak 65 responden $(65 \%)$ sedangkan sebanyak 35 responden (35\%) adalah laki-laki. Ditinjau dari karakteristik usia, diketahui bahwa sebanyak 55

Tabel 1. Karakterisk Responden

\begin{tabular}{lcc}
\hline \multicolumn{1}{c}{ Variabel } & $\mathbf{n = 1 0 0}$ & $\mathbf{\%}$ \\
\hline Jenis Kelamin & & \\
$\quad$ Laki-Laki & 35 & 45 \\
$\quad$ Perempuan & 65 & 55 \\
Usia & & \\
$\quad$ Produktif & 55 & 55 \\
$\quad$ Tidak Produktif & 45 & 45 \\
Status Pekerjaan & & \\
$\quad$ Bekerja & 35 & 35 \\
$\quad$ Tidak Bekerja & 65 & 65 \\
Pengetahuan & & \\
$\quad$ Baik & 20 & 20 \\
$\quad$ Cukup & 30 & 30 \\
$\quad$ Kurang & 50 & 50 \\
Sikap & & \\
$\quad$ Positif & 35 & 35 \\
$\quad$ Negatif & 65 & 65 \\
Upaya Pencegahan Tuberkulosis & & \\
Baik & 21 & 21 \\
$\quad$ Cukup & 34 & 34 \\
$\quad$ Kurang & 45 & 45 \\
\hline Sum : Dataprim, & &
\end{tabular}

Sumber : Data primer, 2015

responden $(55 \%)$ dengan usia produktif, sedangkan 45 responden $(45 \%)$ dengan usia tidak produktif, serta untuk karakteristik status pekerjaan diketahui bahwa sebanyak 65 responden $(65 \%)$ dengan status tidak memiliki pekerjaan, sedangkan sebanyak 35 responden (35\%) dengan status memiliki pekerjaan. Variabel tingkat pengetahuan, responden lebih banyak mempunyai tingkat pengetahuan kurang yaitu sebanyak $50 \%$ responden jika dibandingkan dengan responden yang mem- punyai tingkat pengetahuan cukup yaitu sebanyak 30\% responden dan yang mempunyai tingkat pengetahuan baik yaitu sebanyak $20 \%$ responden. Berdasarkan variabel sikap, maka responden lebih banyak mempunyai sikap negatif, yaitu sebanyak $65 \%$ responden, jika dibandingkan dengan responden yang mempunyai sikap positif sebanyak $35 \%$. Berdasarkan variabel upaya pencegahan, maka responden lebih banyak memiliki upaya pencegahan tuberkulosis yang kurang yaitu sebanyak $45 \%$ responden jika dibandingkan dengan responden yang mempunyai upaya pencegahan tuberkulosis yang cukup yaitu sebanyak $34 \%$ dan responden yang mempunyai upaya pencegahan tuberkulosis yang baik sebanyak $21 \%$.

Berdasarkan data yang ditunjukkan pada Tabel 2, diketahui bahwa 20 responden yang memiliki pengetahuan baik, 15 responden $(75 \%)$ diantaranya memiliki upaya pencegahan tuberkulosis yang baik, dari 30 responden yang memiliki pengetahuan cukup, 27 responden $(55,9 \%)$ diantaranya memiliki upaya pencegahan tuberkulosis yang cukup dan dari 50 responden yang memiliki pengetahuan kurang, 41 responden (82\%) memiliki upaya pencegahan tuberkulosis yang kurang. Selain itu, hasil data bivariat yang diperoleh dari penelitian menunjukan bahwa dari 20 responden yang memiliki pengetahuan baik masih terdapat 2 responden $(10 \%)$ diantaranya memiliki upaya pencegahan tuberkulosis yang kurang, dari 30 responden yang memiliki pengetahuan cukup masih terdapat $6,7 \%$ responden diantaranya memiliki upaya pencegahan tuberkulosis yang kurang dan dari 50 responden yang memiliki pengetahuan kurang terdapat 5 responden (10\%) memiliki upaya pencegahan tuberkulosis yang baik.

Tabel 2 menunjukan bahwa dari 35 responden yang memiliki sikap positif, 19 responden $(54,3 \%)$ diantarnya memiliki upaya pencegahan tuberkulosis yang baik dan dari 65 responden yang memiliki sikap negatif, 44 responden $(67,7 \%)$ diantaranya memiliki upaya pencegahan tuberkulosis yang kurang. Selain itu, hasil data yang didapat dari responden juga menunjukan bahwa dari 35 responden yang memiliki sikap positif masih terdapat 1 responden $(2,9 \%)$ yang memiliki upaya pencegahan tuberkulosis yang kurang dan dari 65 responden yang memiliki sikap negatif masih terdapat 2 responden $(3,1 \%)$ yang memiliki upaya 


\begin{tabular}{|c|c|c|c|c|c|c|c|c|c|}
\hline \multirow{3}{*}{ Variabel } & \multicolumn{6}{|c|}{ Upaya Pencegahan Tuberculosis } & \multirow{2}{*}{\multicolumn{2}{|c|}{ Total }} & \multirow{3}{*}{$\mathbf{p}$} \\
\hline & \multicolumn{2}{|c|}{ Baik } & \multicolumn{2}{|c|}{ Cukup } & \multicolumn{2}{|c|}{ Kurang } & & & \\
\hline & $\mathbf{n}$ & $\%$ & $\mathbf{n}$ & $\%$ & $\mathbf{n}$ & $\%$ & $\mathbf{n}$ & $\%$ & \\
\hline \multicolumn{10}{|l|}{ Pengetahuan } \\
\hline Baik & 15 & 75 & 3 & 15 & 2 & 10 & 20 & 100 & 0,000 \\
\hline Cukup & 1 & 3,3 & 27 & 90 & 2 & 6,7 & 30 & 100 & \\
\hline Kurang & 5 & 10 & 4 & 78 & 41 & 82 & 50 & 100 & \\
\hline \multicolumn{10}{|l|}{ Sikap } \\
\hline Positif & 19 & 54,2 & 15 & 42,9 & 1 & 2,9 & 52 & 100 & 0,000 \\
\hline Negatif & 2 & 3,1 & 19 & 29,2 & 44 & 67,7 & 48 & 100 & \\
\hline
\end{tabular}

Sumber: Data Primer, 2015

pencegahan tuberkulosis yang baik. Hasil penelitian menunjukan bahwa terdapat hubungan yang signifikan antara pengetahuan dan sikap dengan upaya pencegahan tuberkulosis pada masyarakat $(\mathrm{p}<0,1)$.

\section{PEMBAHASAN}

Hasil penelitian yang dilakukan menunjukkan bahwa sebagian responden memiliki pengetahuan yang kurang, yaitu sebesar 50 responden $(50 \%)$. Hal ini disebabkan kurangnya informasi yang didapatkan oleh responden dari media massa seperti buku, televisi ataupun radio dan juga dari puskesmas terdekat yang memberikan penyuluhan tentang penyakit tuberkulosis. Tenaga kesehatan harus bekerjasama dengan masyarakat dalam rangka meningkatkan upaya edukatif pada masyarakat yang masih memiliki pemahaman bahwa tuberkulosis paru merupakan penyakit kutukan. Faktor lain yang menyebabkan kurangnya pengetahuan masyarakat mengenai penyakit tuberkulosis Paru karena tingkat pendidikan responden yang dominan SMA. ${ }^{9}$ Masyarakat banyak yang tidak mengetahui bahwa sumber penularan penyakit tuberkulosis Paru adalah pasien Tuberkulosis BTA positif. Pada waktu batuk atau bersin, pasien menyebarkan kuman ke udara dalam bentuk percikan dahak (droplet nuclei). Sekali batuk dapat menghasilkan sekitar 3000 percikan dahak. Pada umumnya penularan terjadi dalam ruangan dengan percikan dahak berada dalam waktu yang lama. ${ }^{10}$

Sikap positif yang ditemukan pada sebanyak 35 responden (35\%) seperti perlu adanya pemahaman yang baik tentang penyakit tuberkulosis, baik dari penyebab, penularan ataupun gejala ataupun pemeriksaan secara berkala harus dilaksanakan sebagai langkah pencegahan. Pengetahuan dan pemahaman seseorang tentang penyakit tuberkulosis dan pencegahan penularannya memegang peranan penting dalam keberhasilan upaya pencegahan penularan penyakit tuberkulosis. Sebagian responden menyatakan bahwa tidak perlu adanya pencegahan lebih dini dari keluarga terkait penyakit dikarenakan pelayanan kesehatan jauh dari tempat tinggal, sehingga responden akan melakukan kontrol apabila ingin atau saat keluarga mengalami keluhan. Masyarakat cenderung mengabaikan adanya kemungkinan timbulnya penyakit yang lebih serius dan menggangap tidak ada keluhan, penyakit akan sembuh dengan sendirinya. Namun, apabila ada keluhan, maka masyarakat baru akan memikirkan untuk melakukan pengobatan. ${ }^{6}$ Masyarakat mengabaikan adanya kemungkinan timbulnya penyakit yang lebih serius. Sikap negatif yang ditunjukkan responden tersebut menyebabkan seorang tidak melakukan pencegahan tuberkulosis, disebabkan oleh tidak mau menerima kenyataaan, bahwa dirinya menderita sesuatu penyakit serta pemikiran, bahwa penyakit tersebut tidak mungkin dapat disembuhkan menyebabkan sikap apatis dari seseorang untuk tidak melakukan pencegahan terhadap penyakit tuberkulosis. Dari hal tersebut sikap sangat berhubungan dengan upaya pencegahan terhadap penyakit tuberkulosis. ${ }^{9}$

Hasil penelitian juga menunjukkan bahwa sebagian besar responden penelitian yang memiliki upaya pencegahan tuberkulosis yang kurang, yaitu sebanyak 45 responden (45\%). Sebagian responden $(13,63 \%)$ mengabaikan salah satu upaya pencegahan yang penting misalnya saja tidak membuka jendela di pagi hari agar terjadi 
pertukaran udara di dalam rumah sehingga udara di rumah segar. Tindakan yang tidak dilakukan oleh responden tersebut merupakan salah satu upaya pencegahan yang dilakukan untuk menurunkan angka kejadian penyakit tuberkulosis. Upaya pencegahan tersebut terdiri dari menyediakan nutrisi yang baik, pola hidup yang bersih, sanitasi yang adekuat, perumahan yang tidak terlalu padat dan udara yang segar merupakan tindakan yang efektif dalam pencegahan tuberkulosis. ${ }^{11}$

Hal ini disebabkan walaupun pengetahuan masyarakat tentang upaya pencegahan tuberkulosis sudah baik, tetapi konsistensi dengan upaya pencegahan tuberkulosis masih ada yang kurang. Misalnya, masih ada masyarakat yang tidak menutup mulut saat bersin atau batuk, walaupun mereka sebenarnya mengetahui bahwa menutup mulut saat bersin atau batuk merupakan salah satu upaya pencegahan tuberkulosis. ${ }^{12}$ Namun, masyarakat yang memiliki pengetahuan kurang, tetapi memiliki upaya pencegahan tuberkulosis disebabkan adanya keinginan atau rasa takut tertular penyakit tuberkulosis.

Penelitian ini sejalan dengan penelitian Wahyuni yang menyimpulkan bahwa terdapat hubungan yang bermakna antara pengetahuan dengan perilaku pencegahan penularan penyakit tuberkulosis di wilayah kerja Puskesmas Bendosari $(p=0,000)$. Semakin baik tingkat pengetahuan maka semakin tinggi juga tindakan pencegahan penularan penyakit tuberkulosis yang dilakukan. ${ }^{7}$ Media melakukan penelitian yang berjudul "Pengetahuan, Sikap dan Perilaku Masyarakat tentang Penyakit Tuberkulosis Paru di Kecamatan Sungai Tarab, Kabupaten Tanah Datar Provinsi Sumatera Barat". Hasil penelitian ini menunjukkan bahwa pengetahuan sebagian masyarakat mengenai gejala penyakit tuberkulosis relatif cukup baik, sikap masyarakat masih kurang peduli terhadap akibat yang dapat ditimbulkan oleh penyakit tuberkulosis, perilaku dan kesadaran sebagian masyarakat untuk memeriksakan dahak dan menggunakan fasilitas pelayanan kesehatan masih kurang, karena mereka malu dan takut divonis menderita tu-

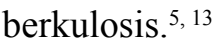

Penelitian ini sejalan dengan penelitian Suhardi, yang menunjukkan ada hubungan antara pengetahuan responden tentang tuberkulosis dengan kejadian tuberkulosis di wilayah Puskesmas
Pringsurat Kabupaten Temanggung $(\mathrm{p}=0,042)$. Dari pertanyaan yang diajukan menunjukkan banyak responden yang belum mengetahui tuberkulosis menular lewat percikan dahak (89\%), merokok dapat memperbesar kemungkinan tuberkulosis $(69,2 \%)$, dan tidur terpisah dengan penderita tuberkulosis merupakan pencegahan penularan tuberkulosis $(72 \%) .{ }^{14}$

Pengetahuan atau kognitif merupakan domain yang sangat penting dalam membentuk tindakan seseorang (overt behavior). Pengetahuan yang baik apabila tidak ditunjang dengan sikap yang positif yang diperlihatkan akan memengaruhi seseorang untuk berperilaku, seperti yang diungkapkan Notoatmodjo yang menyatakan bahwa domain dari perilaku adalah pengetahuan, sikap dan tindakan.

Hal ini disebabkan walaupun sikap masyarakat tentang upaya pencegahan tuberkulosis bersifat positif, tetapi sikap seseorang menunjukkan sikap atau perilaku tertentu karena dengan dengan bersikap itu dia memperoleh sesuatu yang menyenangkan. Namun, sikap juga dapat terbentuk hanya karena meniru orang lain, misalnya saja seseorang hanya bersikap positif dalam hal mencegah tuberkulosis karena meniru orang tuanya. ${ }^{13}$ Masyarakat yang memiliki sikap kurang, tetapi memiliki upaya pencegahan tuberkulosis baik disebabkan adanya keinginan atau rasa takut tertular penyakit tuberkulosis namun memiliki pengetahuan yang kurang sehingga mereka tidak mengetahui bahwa yang dilakukan dapat menyebabkan penularan tuberkulosis. Penderita tuberkulosis paru harus menjaga kontak terhadap keluargannya yang sehat yaitu mengurangi kontak dengan keluarga lainnya untuk sementara selama pengobatan terutama kelompok yang rentan terhadap penularan yaitu bayi dan lansia ${ }^{15}$.

Faktor lain yang menyebabkan sikap negatif terhadap pencegahan tuberkulosis, adalah jarang sekali pelaksanaan kontrol rutin 6 bulan sekali, menggunakan masker debu, pemeriksaan dahak, serta adanya pengaruh faktor emosional dari penderita. Sebagian responden berusia muda mempunyai emosi yang terkadang-kadang (malas) untuk pergi berobat atau mengontrol kesehatan, memakai masker debu, pemeriksaan dahak, dan malas untuk berobat dengan alasan jauh dari tempat tinggal mereka. Sehingga mereka akan 
melakukan kontrol apabila ingin atau saat keluarga mereka mengalami keluhan saja. Mereka mengabaikan adanya kemungkinan timbulnya penyakit yang lebih serius, dan mereka menggangap tidak ada keluhan penyakit sembuh jika ada keluhan mereka berobat. ${ }^{6}$

Hasil penelitian menunjukkan adanya hubungan yang signifikan antara sikap dengan upaya pencegahan tuberkulosis. Penelitian ini sejalan dengan penelitian Djannah sikap responden tentang perilaku pencegahan penularan penyakit tuberkulosis di Sleman Yogyakarta didapatkan sebagian besar memiliki sikap yang baik. Sikap positif dalam penelitian ini terdiri dari responden mendukung dengan upaya pencegahan penyakit tuberkulosis, cara penularan, dan faktor risiko yang menyebabkan penyakit tuberkulosis terjadi. Sikap negatif dalam penelitian ini terdiri dari beberapa responden kurang mendukung dengan beberapa upaya pencegahan dan faktor risiko yang dapat menyebabkan penyakit tuberkulosis. Hal ini disebabkan responden kurang informasi tentang penyakit tuberkulosis, memiliki pengalaman yang kurang tentang upaya pencegahannya dan dapat juga disebabkan oleh pengaruh orang lain atau kebudayaan dalam pengambilan sikap dari responden. ${ }^{16}$

Penelitian yang dilakukan oleh Suhardi sejalan dengan hasil penelitian ini, yaitu terdapat hubungan antara sikap dengan perilaku pencegahan penyakit tuberkulosis paru di wilayah Puskesmas Pringsurat Kabupaten Temanggung, dengan nilai $\mathrm{p}=0,032 .{ }^{14}$ Penelitian lain yang mendukung hasil penelitian ini adalah hasil penelitian dari Wahyuni yang menyebutkan bahwa terdapat hubungan antara sikap dengan perilaku pencegahan penularan tuberkulosis paru dengan nilai $\mathrm{p}=0,000$. Dari pernyataan yang diajukan menunjukkan banyak responden yang setuju dengan pernyataan saya akan memeriksakan diri ke puskesmas saat mengalami gejala batuk berdahak dan bercampur darah (55,9\%), saya akan berhenti merokok apabila merasakan efeknya $(52,9 \%)$, dan tidur terpisah dengan anggota keluarga yang terkena tuberkulosis $(76,5 \%)$.

\section{KESIMPULAN DAN SARAN}

Penelitian ini menyimpulkan bahwa ada hubungan antara pengetahuan $(p=0,000)$ dan sikap $(\mathrm{p}=0,000)$ tentang upaya pencegahan Tuberkulosis pada masyarakat, khususnya pada masyarakat di wilayah kerja Puskesmas Bawahan Selan, sehingga diperlukan adanya upaya intervensi untuk peningkatan pengetahuan pada masyarakat. Adapun saran yang dapat diberikan berdasarkan hasil penelitian ini adalah perlu adanya pemberian Komunikasi, Informasi dan Edukasi (KIE) yang dilakukan oleh tenaga kesehatan bekerjasama dengan kader kesehatan di desa tentang upaya pencegahan tuberkolusis di masyarakat, agar terjadi peningkatan pengetahuan dan keterampilan dalam pencegahan penyakit tuberkulosis sehingga dapat menekan dan mencegah penularan penyakit. Perlu adanya penelitian lebih lanjut yang dilakukan dengan variabel penelitian seperti tingkat pendidikan, jenis pekerjaan dan kondisi fisik rumah serta peran dari petugas kesehatan dan dukungan keluarga terdekat.

\section{UCAPAN TERIMA KASIH}

Peneliti mengucapkan terima kasih kepada Rektor Universitas Lambung Mangkurat dan Dekan Fakultas Kedokteran yang telah memberikan bantuan dana dalam pelaksanaan kegiatan penelitian melalui Skim Hibah Penelitian Kompetitif FK UNLAM. Selain itu, ucapan terima kasih kepada Dinas Kesehatan Kabupaten Banjar dan Kepala Puskesmas Bawahan Selan yang memberikan izin dan memfasilitasi kegiatan penelitian serta Responden Penelitian yang telah memberikan informasi tentang variabel yang diteliti.

\section{DAFTAR PUSTAKA}

1. Wibisono, Yusuf. Buku Ajar Ilmu Penyakit Paru. Surabaya: Departemen Ilmu Penyakit Paru Fakultas Kedokteran UNAIR; 2010.

2. Kementerian Kesehatan RI. Profil Kesehatan Indonesia Tahun 2013. Jakarta: Kementerian Kesehatan RI; 2014.

3. Dinkes Provinsi Kalimantan Selatan. Profil Kesehatan Provinsi Kalimantan Selatan. Banjarmasin: Dinas Kesehatan; 2012.

4. Dinas Kesehatan Kabupaten Banjar. Data Rekapitulasi Hasil Kegiatan Program P2 TB Tahun 2014.

5. Simak, Valen Fridolin, dkk. Hubungan antara Pengetahuan dan Sikap dengan Tindakan Hidup Sehat Pasien TB Paru di Poliklinik Paru 
RSUP Prof Dr. R. D Kandou Manado. ejournal Keperawatan (e-Kp). 2013; 1(1); 1-6.

6. Media Y. Pengetahuan, Sikap dan Perilaku Masyarakat tentang Penyakit Tuberculosis (TB) Paru di Kecamatan Sungai Tarab Kabupaten Tanah Datar Provinsi Sumatera Barat Tahun 2010. Media Litbang Kesehatan. 2011; 21(2):82-88.

7. Wahyuni DS. Hubungan Kondisi Fisik Rumah dan Karakteristik Individu dengan Kejadian Tuberkulosis Paru BTA Positif di Puskesmas Ciputat Kota Tangerang Selatan Tahun 2012. Berkala Ilmiah Mahasiswa Kesehatan Masyarakat Indonesia. 2012;11:1-8.

8. Departemen Kesehatan Republik Indonesia. Bagaimana dengan Indonesia?. Jakarta: 2014.

9. Gendhis ID, dkk. Hubungan antara Pengetahuan, Sikap Pasien dan Dukungan Keluarga dengan Kepatuhan Minum Obat pada Pasien TB Paru di BKPM Pati. Artikel publikasi, 2012.

10. Astuti, Sumiaty. Hubungan Tingkat Pengetahuan dan Sikap Masyarakat Terhadap Upaya Pencegahan Penyakit Tuberkulosis di RW 04 Kelurahan Legoan Jakarta Utara Tahun 2013 [Skripsi]. Jakarta: Universitas Islam Negeri
Syarif Hidayatullah, 2013.

11. Suharyo. Determinasi Penyakit Tuberculosis di Daerah Pedesaan. Jurnal Kesehatan Masyarakat. 2013; 9 (1): 85-91.

12. Friska J. Hubungan Pengetahuan dan Sikap dengan Kepatuhan Minum Obat Anti Tuberculosis pada Pasien Tuberculosis Paru di Puskesmas Kecamatan Jatinegara Tahun 2012. Artikel publikasi, 2012.

13. Notoadmojo S. Promosi Kesehatan dan Ilmu Perilaku. Jakarta: Rineka Cipta, 2007.

14. Suhardi. Hubungan Antara Pengetahuan dan Sikap Pasien TB Paru dengan Perilaku Pencegahan Penularan TB Paru di Wilayah Puskesmas Pringsurat Kabupaten Temenggung Tahun 2008. Artikel Publikasi, 2008.

15. Sambono. Studi Perilaku Siswa SMA Ronevan Tual terhadap Pencegahan HIV/AIDS di Kelurahan Dullah Selatan Kota Tual. Jurnal MKMI. 2013;9(1):1-6.

16. Nurfadillah, Yovi I, Restuastuti T. Hubungan Pengetahuan dengan Tindakan Pencegahan Penularan pada Keluarga Penderita Tuberculosis Paru di Ruang Rawat Inap Paru RSUD Arifin Achmad Provinsi Riau. JOM FK 2014;1(2):1-9. 